\title{
Similarities between terrestrial planets at the time life appeared on Earth
}

\section{Comment on "Mineral self-organization on a lifeless planet" by J.M. García-Ruiz et al.}

\author{
Jorge L. Vago ${ }^{a, *}$, Frances Westall ${ }^{b}$ \\ a European Space Agency, ESTEC, Keplerlaan 1, Noordwijk, the Netherlands \\ ${ }^{\mathrm{b}}$ CNRS-OSUC-Centre de Biophysique Moléculaire, Orléans, France
}

Received 13 May 2020; accepted 13 May 2020

Communicated by E. Di Mauro

Venus, Earth, and Mars differ in size, distance from the Sun, atmospheric composition, and ambient conditions. However, during the first $500 \mathrm{Ma}$ after their formation—approximately $4.56 \mathrm{Ga}$ ago—they probably had comparable surface environments.

Although each terrestrial planet formed mainly from locally sourced materials, the final stages of accretion softened chemical differences by incorporating water and other volatiles from the outer Solar System—shepherded inwards by the wanderings of Jupiter and Saturn [9]. As the three planets cooled, their mantles degassed atmospheres, a large part of whose water later condensed, giving rise to global oceans, or at least, large expanses of water many hundreds of metres deep [1]. We may expect this process to have taken place initially on Mars, then on Earth, and (perhaps) finally on Venus. We include this qualifying "perhaps" because high-altitude water is readily dissociated by ultraviolet light with subsequent loss of hydrogen to space. Some authors believe that Venus' atmosphere may have dried out before its water had a chance to condense [3]; many others disagree [10].

Fuelled by internal heat, rapid material turnover coupled with vigorous hydrothermal circulation brought about the sequestration of most atmospheric $\mathrm{CO}_{2}$ into carbonate minerals. Because the luminosity of the young Sun was $70 \%$ that of today, in the absence of strong greenhouse forcing, surface temperatures would have rapidly plunged to subfreezing values - on Earth and Mars, not on Venus [8]. However, a gradual buildup of $\mathrm{CH}_{4}$, assisted by a generally low planetary albedo (water is dark), alleviated the effect of the rapidly thinning $\mathrm{CO}_{2}$ presence. As water diffused downward through fractured ocean crust, it reacted with mantle rocks at high temperatures to transform into a hydrothermal fluid able to promote serpentinization [4]. Serpentinization produces $\mathrm{H}_{2}$ that can react with oxidized carbon compounds under reducing conditions to emit $\mathrm{CH}_{4}$ and other simple organic molecules in the form of ubiquitous thick, smoke-like underwater plumes [6,5]. And here we connect with the García-Ruiz et al. [2] article.

The paper starts by explaining how, under alkaline conditions, silica can induce the formation of biomimetic structures. The emphasis of this work is not placed on warning investigators about the perils of attempting to identify

\footnotetext{
DOI of original article: https://doi.org/10.1016/j.plrev.2020.01.001.

* Corresponding author.

E-mail address: jorge.vago@esa.int (J.L. Vago).
} 
potential microorganisms on the basis of morphology alone. In fact, those familiar with the analysis of microbial colonies' palaeorelics would likely not be "taken in" by the biomorphs. Rather, the message is another: that the mineral world can, under certain conditions, approximate some of the behaviours we associate with living things, and that this distinction may have once been very much blurred—see also Saladino et al. [7].

The authors propose that, while $\mathrm{CH}_{4}$ levels were important, the terrestrial ocean's $\mathrm{pH}$ would have remained high. We are not so sure. $\mathrm{CO}_{2}$ will readily dissolve in water to give a slightly acidic $\sim \mathrm{pH} 6$ sea, as supported by our analysis of $3.5 \mathrm{Ga}$ samples from the Pilbara and Barberton [11]. However, most of their assertions regarding the mineral scenario's ability to support interesting prebiotic reactions would hold true even for the case where these alkaline environments would be geographically restricted, or even local, or circumscribed to the plumes.

The work mentions the upcoming ExoMars rover and its objective to search for biosignatures in Noachian (4.0+ Ga) Mars deposits [8]. We would really welcome an extension, or a discussion, of the paper's thesis to the Venus and Mars case. For the former, the assumption should be a global ocean with water temperatures in the range $20-60^{\circ}$ during the faint, young Sun period. For the latter, the waters' surface temperatures would have hovered around the freezing point, or below. In both cases, the internal heat of the young planets would have been the engine driving rock-water interactions releasing their warm, organics-rich exhalation in a submarine environment.

\section{Declaration of competing interest}

The authors declare that they have no known competing financial interests or personal relationships that could have appeared to influence the work reported in this paper.

\section{References}

[1] Elkins-Tanton LT. Formation of early water oceans on rocky planets. Astrophys Space Sci 2011;332(2):359-64. https://doi.org/10.1007/ s10509-010-0535-3.

[2] García-Ruiz JM, van Zuilen MA, Bach W. Mineral self-organization on a lifeless planet. Phys Life Rev 2020;1:1-21. https://doi.org/10.1016/ j.plrev.2020.01.001.

[3] Genda H. Origin of Earth's oceans: an assessment of the total amount, history and supply of water. Geochem J 2016;50(1):27-42. https:// doi.org/10.2343/geochemj.2.0398.

[4] Holm NG, et al. Serpentinization and the formation of $\mathrm{H} 2$ and $\mathrm{CH} 4$ on celestial bodies (planets, moons, comets). Astrobiology 2015;15(7):587-600. https://doi.org/10.1089/ast.2014.1188.

[5] Martin W, Russell MJ. On the origins of cells: a hypothesis for the evolutionary transitions from abiotic geochemistry to chemoautotrophic prokaryotes, and from prokaryotes to nucleated cells. Philos Trans R Soc Lond B, Biol Sci 2003;358(1429):59-85. https://doi.org/10.1098/ rstb.2002.1183.

[6] Nisbet EG, Sleep NH. The habitat and nature of early life. Nature 2001;409(6823):1083-91. https://doi.org/10.1038/35059210.

[7] Saladino R, et al. A global scale scenario for prebiotic chemistry: silica-based self-assembled mineral structures and formamide. Biochemistry 2016;55(19):2806-11. https://doi.org/10.1021/acs.biochem.6b00255.

[8] Vago JL, et al. Habitability on early Mars and the search for biosignatures with the ExoMars Rover. Astrobiology 2017;17(6-7):471-510. https://doi.org/10.1089/ast.2016.1533.

[9] Walsh KJ, et al. A low mass for Mars from Jupiter's early gas-driven migration. Nature 2011;475(7355):206-9. https://doi.org/10.1038/ nature10201. Nature Publishing Group.

[10] Way MJ, et al. Was Venus the first habitable world of our solar system? Geophys Res Lett 2016;43(16):8376-83. https://doi.org/10.1002/ 2016GL069790.

[11] Westall F, et al. A hydrothermal-sedimentary context for the origin of life. Astrobiology 2018;18(3):259-93. https://doi.org/10.1089/ast.2017. 1680. 